European Journal of Sustainable Development Research

2019, 3(1), em0070

ISSN: $2542-4742$

\title{
Biochemical Pathway for Hydrogen Production Using Coffee Cut-Stems as Raw Material
}

\author{
Carlos Andrés García-Velásquez ${ }^{1}$, Carlos Ariel Cardona Alzate ${ }^{1 *}$ \\ ${ }^{1}$ Universidad Nacional de Colombia Sede Manizales, Carrera. 27 No. 64-60, 170003 Manizales, COLOMBIA
}

*Corresponding Author: ccardonaal@unal.edu.co

Citation: García-Velásquez, C. A. and Cardona Alzate, C. A. (2019). Biochemical Pathway for Hydrogen Production Using Coffee Cut-Stems as Raw Material. European Journal of Sustainable Development Research, 3(1), em0070. https://doi.org/10.20897/ejosdr/3949

Published: February 6, 2019

\begin{abstract}
In coffee-producing countries such as Colombia, Coffee Cut-Stems (CCS) as waste is abundant, either from cuts or renovation. On average, 17 tonnes of dry wood per hectare can be obtained from the renovation. These residues would serve to produce, approximately, 690 GWe every year; however, the energy content of these residues is not properly used and the direct emissions related to their combustion are relatively high. Based on this statement, this paper performs the techno-economic, energetic and environmental assessment for hydrogen production through dark fermentation using CCS as raw material aiming to improve the economic valorization of this wood waste. Low productivities, low energy performance, and high environmental impacts are obtained when considering the stand-alone production of hydrogen; nevertheless, the energetic valorization of by-products (ethanol, acetic acid and butyric acid) improved the profitability, energy performance and environmental impacts of the process scheme. Therefore, it is very understandable that the stand-alone ways for hydrogen production are not yet the solution, and different approaches should be included such as the integrated biorefinery pathways.
\end{abstract}

Keywords: hydrogen, dark fermentation, stand-alone vs. biorefinery pathways

\section{INTRODUCTION}

Hydrogen is a promising energy source that can serve as an energy carrier or as a storage fuel aiming to replace fossil fuels in a wide range of applications (U.S Energy Information Administration (EIA), 2018). It could be implemented as a long-term energy carrier with less environmental issues, especially without $\mathrm{CO}_{2}$ emissions (Parthasarathy and Narayanan, 2014). The future implementation of the hydrogen as energy carrier depends primarily upon four factors: (i) the future cost of hydrogen, (ii) The advance of the technologies for hydrogen production, (iii) long-term restrictions on greenhouse gases and (iv) the cost of competing energy systems, mainly, fossil fuels (Balat, 2008).

Traditionally, technologies for hydrogen production can be divided into thermochemical methods (steam methane reforming, gasification, pyrolysis, and combustion), electrochemical methods (electrolysis and photolysis) and biochemical methods (dark fermentation and photo-fermentation). Biological methods are considered as a promising way of producing hydrogen as they provide a feasible route for the sustainable supply of $\mathrm{H}_{2}$ with low pollution and moderate efficiency (Wu and Chang, 2007). Dark and Photo fermentation are complex processes that involve diverse groups of bacteria where simple sugars or disaccharides are converted into hydrogen, carbon dioxide and organic acids (Urbaniec and Bakker, 2015).

Several authors have studied the production of biohydrogen through dark fermentation using different microorganisms; however, the Thermoanaerobacterium thermosaccharolyticum is a well-known strain for its high hydrogen 
yield and the ability to utilize different types of substrates (Kumar et al., 2018). One of the first researchers that used this strain for bio-hydrogen production was Ren et al., (Ren et al., 2010) who studied the effect of the enzymatic hydrolysis of corn stover in the production of hydrogen using the strain T. Thermosaccharolyticum W16. The microorganism was able to degrade the corn stover enzymatic hydrolysate $\left(11.2 \mathrm{~g} \mathrm{~L}^{-1}\right.$ glucose and $3.4 \mathrm{~g} \mathrm{~L}^{-1}$ xylose) in higher proportion than when pure sugars (glucose and xylose) were used as carbon sources. The main products from the fermentation were hydrogen $\left(3.3 \mathrm{~L} \mathrm{H}_{2} / \mathrm{L}\right)$, acetate $(63 \mathrm{mM})$ and butyrate $(23 \mathrm{mM})$. Recently, common residues from different agroindustrial applications have been considered for the production of biohydrogen such as sugarcane bagasse and oil palm trunks. Hu et al., (Hu et al., 2018) studied the production of biohydrogen from the non-detoxified sugarcane bagasse (NDSCB) using the strain T. thermosaccharolyticum MJ1. The NDSCB was obtained from a previous dilute-acid hydrolysis pretreatment and then, sent to a two-stage anaerobic fermentation. Hydrogen $\left(6.2 \mathrm{~L} \mathrm{H}_{2} / \mathrm{L}\right)$, butyrate $(17.2 \mathrm{mM})$ and acetate $(8.5 \mathrm{mM})$ are obtained as main products from this process. On the other hand, Sitthikitpanya et al., (Sitthikitpanya et al., 2017) studied the production of biohydrogen followed by a methane production from oil palm trunk hydrolysate (lime treatment and enzymatic saccharification) using the strain T. themosaccharobyticum KKU19. The highest hydrogen yield was 2.18 $\mathrm{L} \mathrm{H}_{2} / \mathrm{L}$ and no other metabolites were quantified. Consequently, it is noteworthy the potential use of different lignocellulosic biomass for the production of hydrogen with high yields and other metabolites of industrial interest.

Another important parameter that has direct influence in the future implementation of the dark fermentation at industrial level is the energy efficiency since most of the fermentative processes have high energy requirements, especially in the pretreatment and fermentation stages. In this sense, Ruggeri et al., (Ruggeri et al., 2010) developed an energy analysis of the dark anaerobic fermentation for hydrogen production considering different operative conditions and reactor scales. According to the author, particular care has to be taken in the raw material treatment, the energy recovery and the warming strategies in the production of hydrogen for energy purposes. On the other hand, different by-products (volatile fatty acids) are produced from the dark fermentation; the energetical valorization of these metabolites should be considered aiming to improve the overall energy performance of the process. In this sense, Zhang et al., (Zhang et al., 2017) evaluated the production of hydrogen from Platanus Orientalis followed by the methane production using the effluents from the dark - and photo- fermentations. As main result, the authors concluded that the valorization of the effluents from the dark fermentation can increase the energy efficiency from $4.3 \%$ to $22.28 \%$.

The main goal of this paper is to perform the techno-economic, energetic and environmental assessment of the hydrogen production through dark fermentation using as raw material Coffee Cut-Stems (CCS). The valorization of the metabolites from the fermentation broth was considered in order to evaluate the influence of these by-products in the profitability, energy performance and environmental impact of the hydrogen production using T. Thermosaccharolyticum. For this purpose, two scenarios were proposed: i) stand-alone production of hydrogen and ii) the biorefinery concept.

\section{METHODS}

\section{Coffee Cut-Stems (CCS) as Raw Material}

Coffee Cut-Stems are composed of cellulose (40.39\%), hemicellulose (34.01\%), lignin (10.13\%), extractives $(14.18 \%)$ and ash (1.27\%) (García et al., 2017). High holocellulose (cellulose and hemicellulose) and low lignin contents provide a suitable scenario for the production of fermentable sugars aiming to produce bioenergy and/or biochemicals (Rodríguez Valencia and Zambrano Franco, 2010). This raw material has been widely studied for the production of different products such as ethanol, hydrogen, furfural, nonane and hydroxymethylfurfural (HMF) (Aristizábal et al., 2015; García et al., 2017; Triana et al., 2011).

\section{Simulation Procedure}

The main objective of this procedure was to conceptually design the scenario, in a biorefinery way, that makes the hydrogen production process more profitable and environmentally friendly in comparison to the stand-alone pathway. The economic overview of the scenarios was assessed in terms of the contribution of the main economic parameters, the hydrogen and by-products sales and finally, the revenues of the process scheme. Additionally, the energy targets of each scenario were determined in order to establish the botspots of the fermentative scenarios. There must be a balance between the economic profitability and environmental impacts of the process. Consequently, the Waste Reduction Algorithm (WAR) was used as simulation tool to evaluate the performance of the process in eight (8) impact categories. A detailed description of the scenarios, the processes and the parameters involved in the simulation procedure is presented below. 


\section{Scenario 1}
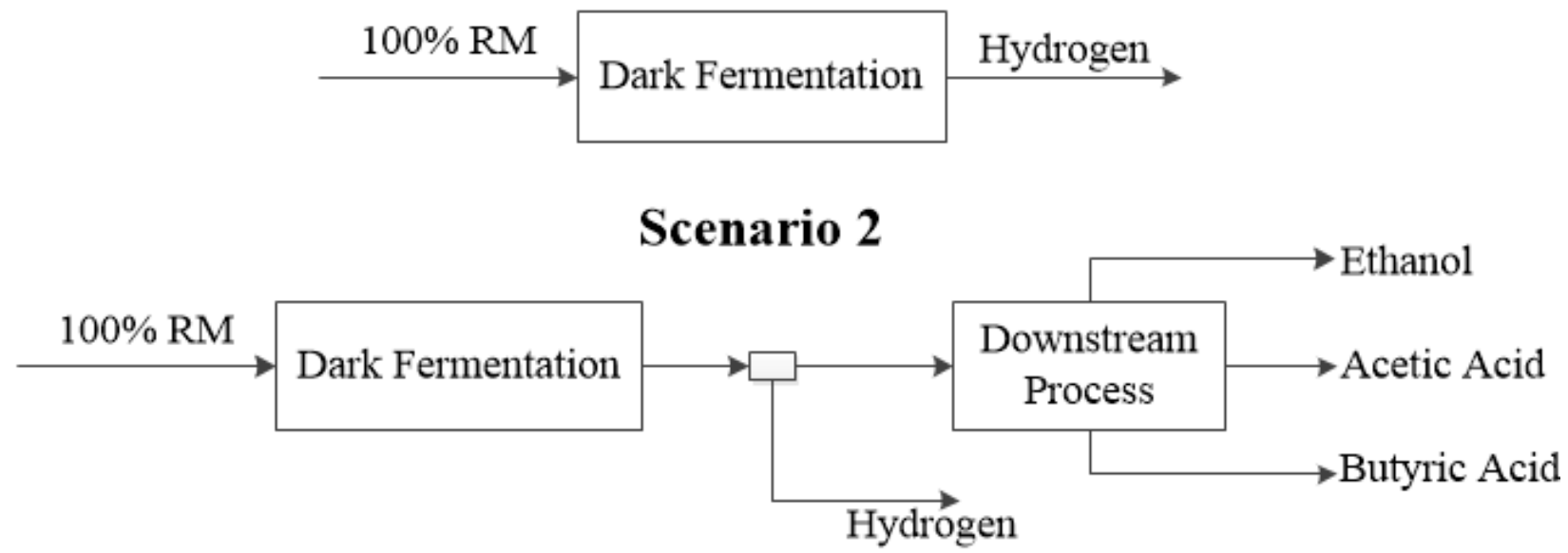

Figure 1. Stand-alone and biorefinery pathways for hydrogen production. $* \mathrm{RM}=$ Raw Material

\section{Scenarios}

Two dark fermentation scenarios were proposed to evaluate the effect of the valorization of by-products in the economic, energetic and environmental assessment of the hydrogen production. The stand-alone pathway involved the production of hydrogen as a single product from the dark fermentation, whereas the biorefinery pathway considered the separation, purification and valorization of secondary metabolites from the fermentation broth. Figure 1 presents the description of the two evaluated scenarios considering four products (hydrogen, ethanol, acetic acid and butyric acid) from the dark fermentation scenarios, based on the data reported in the literature for the T. Thermosaccharolyticum (Cao et al., 2009; Ren et al., 2010).

\section{Process Description}

Kinetic models reported in the literature were used as starting point for the conceptual design of the different process schemes for hydrogen production using the software Aspen Plus V8.0 (Aspen Technology, Inc, USA). From this procedure, mass and energy balances were obtained and then, they were used to evaluate the economic profitability, energy performance and environmental impact of the proposed scenarios. Mathematical modeling of the concentration profiles using kinetic models was performed in software packages such as Matlab (MathWorks, USA).

For simulation purposes, the thermodynamic model Non-Random Two Liquids (NRTL) was used to analyze the behavior of the liquid phase and the Hayden $O^{\prime}$ Connell equation of state was selected to describe the vapor phase (López et al., 2009). Additional data such as physical properties were obtained from the work of Wooley and Putsche (Wooley and Putsche, 1996).

\section{Dark Fermentation}

The production of hydrogen through dark fermentation involved various stages: pretreatment of the raw materials, fermentation, hydrogen purification, ethanol and VFA (volatile fatty acids) separation. The pretreatment of the raw material consisted mainly of physical and chemical treatments. The physical treatment involved a drying process of the raw material to achieve a moisture content below $10 \%$. Subsequently, the lignocellulosic biomass was milled to obtain a particle size of $0.25 \mathrm{~mm}$. Due to the high crystallinity and low biodegradability, lignocellulosic biomass may require a chemical treatment prior to fermentation processes (Nissilä et al., 2014). For this reason, a mild-acid pretreatment and enzymatic hydrolysis were proposed as methods for raw material pretreatment. Acid hydrolysis with sulfuric acid $(2 \% \mathrm{w} / \mathrm{w})$ at $130^{\circ} \mathrm{C}$ and solid to liquid ratio of $1: 10$ were used as conditions in the simulation procedure. Hydrolysis yields were calculated based on the kinetic expression reported by Rafiqul et al., (Rafiqul and Sakinah, 2012). Table 1 presents the kinetic model and parameters used in the modeling of the acid hydrolysis where xylose, glucose, furfural and acetic acid are obtained as main products. The main objective of the CCS acid hydrolysis is to increase the accessibility of the cellulose for the enzymatic treatment. Nevertheless, one problem associated with the dilute-acid hydrolysis is the formation of toxic compounds such as furfural and phenolic compounds. As a consequence, alkaline treatment with $\mathrm{Ca}(\mathrm{OH})_{2}$ is widely used in the hydrolysates detoxification (Taherzadeh et al., 2000). The simulation procedure of the alkaline treatment consisted of the degradation of furan compounds and consequently, the formation of gypsum that was separated from the hydrolysate by filtration. Based on the data provided by Purwadi et al., (Purwadi et al., 2004), it was assumed that 
Table 1. Kinetic model and parameters used in the dilute-acid hydrolysis of CCS

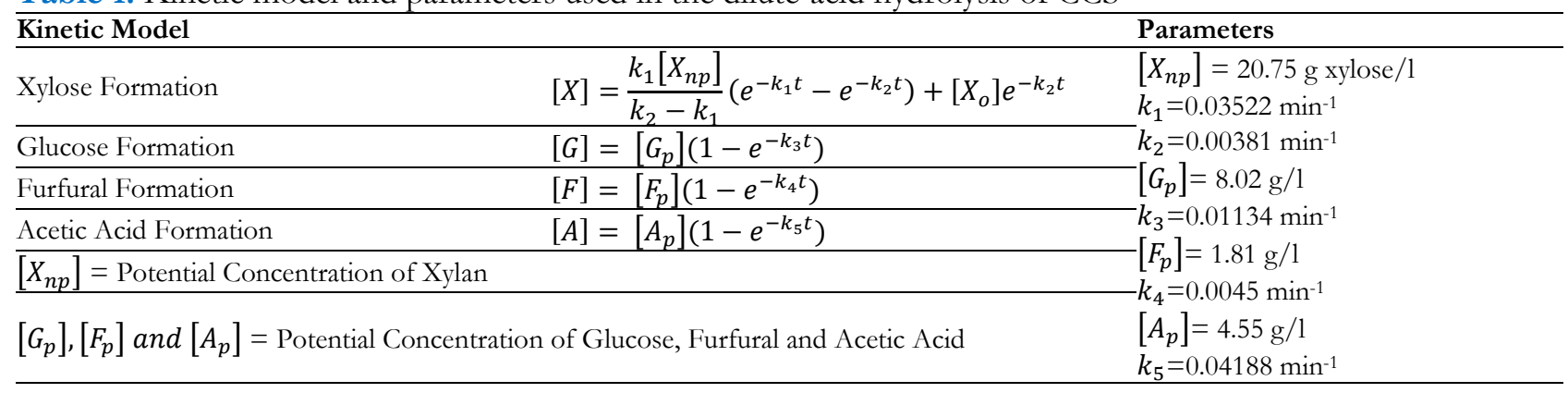

Table 2. Kinetic model and parameters used in the enzymatic saccharification of CCS

\begin{tabular}{|c|c|c|}
\hline Kinetic Model & & Parameters \\
\hline \multirow{3}{*}{ Cellulose to Cellobiose } & $k_{1, r} C_{E_{1 B}} R_{S} C_{S}$ & $k_{1 r}=22.3 \mathrm{~g} \cdot \mathrm{mg}^{-1} \cdot \mathrm{h}^{-1}$ \\
\hline & 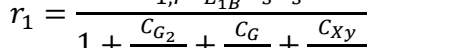 & $k_{2 r}=7.18 \mathrm{~g} \cdot \mathrm{mg}^{-1} \cdot \mathrm{h}^{-1}$ \\
\hline & $1+\overline{K_{1 I G 2}}+\overline{K_{1 I G}}+\overline{K_{1 I X y}}$ & $k_{3 r}=285.5 \mathrm{~g} \cdot \mathrm{mg}^{-1} \cdot \mathrm{h}^{-1}$ \\
\hline \multirow{3}{*}{ Cellulose to Glucose } & $r=\frac{k_{2, r}\left(C_{E_{1 B}}+C_{E_{2 B}}\right) R_{S} C_{S}}{r}$ & $E_{a_{1}}=E_{a_{2}}=E_{a_{3}}=-23190 \mathrm{~J} \cdot \mathrm{mol}^{-1}$ \\
\hline & $r_{2}=\overline{1+\frac{C_{G_{2}}}{V}+\frac{C_{G}}{V}+\frac{C_{X y}}{V}}$ & $K_{1 I G 2}=0.015 \mathrm{~g} / 1$ \\
\hline & $\begin{array}{llll}11 & K_{2 I G 2} & K_{2 I G} & K_{2 I X y} \\
& & C\end{array}$ & $-K_{1 I G}=0.1 \mathrm{~g} / 1$ \\
\hline \multirow{2}{*}{ Cellobiose to Glucose } & $r_{3}=\frac{k_{3, r} C_{E_{2 F}} C_{G_{2}}}{r}$ & $K_{1 I X y}=0.1 \mathrm{~g} / 1$ \\
\hline & $K_{3 M}\left(1+\frac{C_{G}}{K_{3 I G}}+\frac{C_{X y}}{K_{3 I X y}}\right)+C_{G_{2}}$ & $K_{2 I G 2}=132.0 \mathrm{~g} / 1$ \\
\hline Enzyme Adsorption & $C_{E_{i B}}=\frac{E_{i_{\max }} K_{i a d} C_{E_{i F}} C_{S}}{1+K_{i a d} C_{E_{i f}}}$ & $\begin{array}{l}-K_{2 I G}=0.04 \mathrm{~g} / 1 \\
K_{2 I X y}=0.2 \mathrm{~g} / 1 \\
K_{3 I X y}=201 \mathrm{~g} / 1\end{array}$ \\
\hline Enzyme & $C_{E_{i T}}=C_{E_{i F}}+C_{E_{i B}}$ & $K_{3 M}=24.3 \mathrm{~g} / 1$ \\
\hline Substrate Reactivity & $R_{S}=\frac{C_{s}}{S_{o}}$ & $\begin{array}{l}E_{1 \max }=0.06 \mathrm{~g} / \mathrm{g} \\
E_{2 \max }=0.01 \mathrm{~g} / \mathrm{g}\end{array}$ \\
\hline Temperature Dependence & $k_{i r}=k_{i r\left(T_{I}\right)} \exp \left(-\frac{E_{a i}}{R T}\right)$ & $\begin{array}{l}E_{a, 1}=111600 \mathrm{~J} \cdot \mathrm{mol}^{-1} \\
K_{1}=0.4 \mathrm{~g} / \mathrm{g}\end{array}$ \\
\hline \multicolumn{2}{|c|}{$C_{G_{2}}$ [Cellobiose], $C_{G}\left[\right.$ Glucose], $C_{X y}$ [Xylose], $C_{S}$ [Cellulose $]$} & $K_{2 a d}=0.1 \mathrm{~g} / \mathrm{g}$ \\
\hline
\end{tabular}

$80 \%$ of the furan compounds were removed from the xylose-rich liquid. The unconverted fraction of cellulose from the acid hydrolysis can be used to produce glucose by enzymatic saccharification. Enzymatic hydrolysis of CCS was simulated based on the kinetic expressions reported by Zheng et al., (Zheng et al., 2009), Khodaverdi et al., (Khodaverdi et al., 2012) and Kadam et al., (Kadam et al., 2004). Table 2 presents the kinetic model and the parameters used in the enzymatic hydrolysis of CCS. This model correlates the degradation of cellulose and cellobiose with the formation of glucose considering the enzyme charge (cellulase and $\beta$-glucosidase) at $60^{\circ} \mathrm{C}$.

The hydrolysate from the acid and enzymatic hydrolysis was used as carbon source for hydrogen production by the moderate thermophile Thermoanaerobacterium thermosaccharolyticum. Cell growth and substrate consumption were simulated based on the Monod model and the parameters determined by O-Thong et al., (O-Thong et al., 2008) and the formation of the products was described based on the Luedeking-Piret model (Wang and Wan, 2009). Table 3 presents the kinetic models and parameters used in the simulation of the dark fermentation. Hydrogen, carbon dioxide and other metabolites (ethanol, acetic and butyric acid) were the main products from the dark fermentation. The separation of hydrogen from the other gaseous species was performed using coupled porous and non-porous membranes in order to enhance the hydrogen selectivity, which was deeply studied by Bélafi-Bakó et al., (Belafibako et al., 2006). During the fermentation, four gaseous species were produced: water vapor, hydrogen, carbon dioxide and nitrogen. The direct separation of hydrogen from $\mathrm{CO}_{2}$ and $\mathrm{N}_{2}$ seems to be too difficult; therefore, a two-step gas separation system can be used to separate first, the mixture $\mathrm{H}_{2}-\mathrm{N}_{2}$ in a nonporous membrane and subsequently, the mixture $\mathrm{H}_{2}-\mathrm{CO}_{2}$ in a porous membrane. At the end of the two-step separation system, a hydrogen content up to $75 \%$ can be reached (Belafibako et al., 2006).

The fermentation broth is mainly composed of VFA's (butyric and acetic acid), ethanol and non-degraded sugars (glucose and xylose). The separation of the VFA's and ethanol from the remaining compounds was carried out based on the concept of the aqueous two-phase system using a polyethylene glycol (PEG)/ $\mathrm{Na}_{2} \mathrm{SO}_{4}(\mathrm{Wu}$ et al., 2010; Wu et al., 2015). Aqueous two-phase partition is a liquid-liquid extraction method broadly used in the separation of inorganic molecules and biomolecules (Wu et al., 2010). The aqueous two-phase process scheme and its operative conditions were adapted from Wu et al., (Wu et al., 2015), Wu et al., (Wu et al., 2010) and Lefranc et al., (Lefranc, 1928). First, $\mathrm{Na}_{5} \mathrm{SO}_{4}$ was mixed with the fermentation broth at $36^{\circ} \mathrm{C}$ to salt out the cell protein, sugars and nitrogen compounds. Then, the liquid fraction was separated from the precipitate by filtration. Subsequently, the broth was added into PEG to form an aqueous and organic phase. The organic phase contained most of the 
Table 3. Kinetic models and parameters used in the simulation of the dark fermentation

\begin{tabular}{|c|c|c|}
\hline Kinetic Model & & Parameters \\
\hline Substrate Uptake & $\frac{d S}{d t}=-u_{\max } * I *\left(\frac{S}{S+K_{S}}\right) * X$ & \multirow{4}{*}{$\begin{array}{l}u_{\max }=0.31 \mathrm{~h}^{-1} \\
K_{s}=1.47 \mathrm{~g} / \mathrm{l} \\
Y_{x / s}=0.135 \mathrm{~g} / \mathrm{g} \\
Y_{1}=0.0127 \mathrm{~g} / \mathrm{g} \\
Y_{2}=0.1928 \mathrm{~g} / \mathrm{g} \\
Y_{3}=0.1278 \mathrm{~g} / \mathrm{g} \\
Y_{4}=0.1597 \mathrm{~g} / \mathrm{g} \\
Y_{5}=0.0521 \mathrm{~g} / \mathrm{g} \\
p H_{u}=7 \\
p H_{i}=4\end{array}$} \\
\hline pH Inhibition & $I=\exp \left(-3 *\left(\frac{p H-p H_{u}}{p H_{u}-p H_{i}}\right)^{2}\right)$ & \\
\hline Biomass Growth & $\frac{d X}{d t}=-Y_{x / s} * \frac{d S}{d t}$ & \\
\hline Products Formation & $\begin{array}{l}\frac{d H_{2}}{d t}=-Y_{1} * \frac{d S}{d t} \\
\frac{d A c}{d t}=-Y_{2} * \frac{d S}{d t} \\
\frac{d B u t}{d t}=-Y_{3} * \frac{d S}{d t} \\
\frac{d C O_{2}}{d t}=-Y_{4} * \frac{d S}{d t} \\
\frac{d E t o H}{d t}=-Y_{5} * \frac{d S}{d t}\end{array}$ & \\
\hline
\end{tabular}

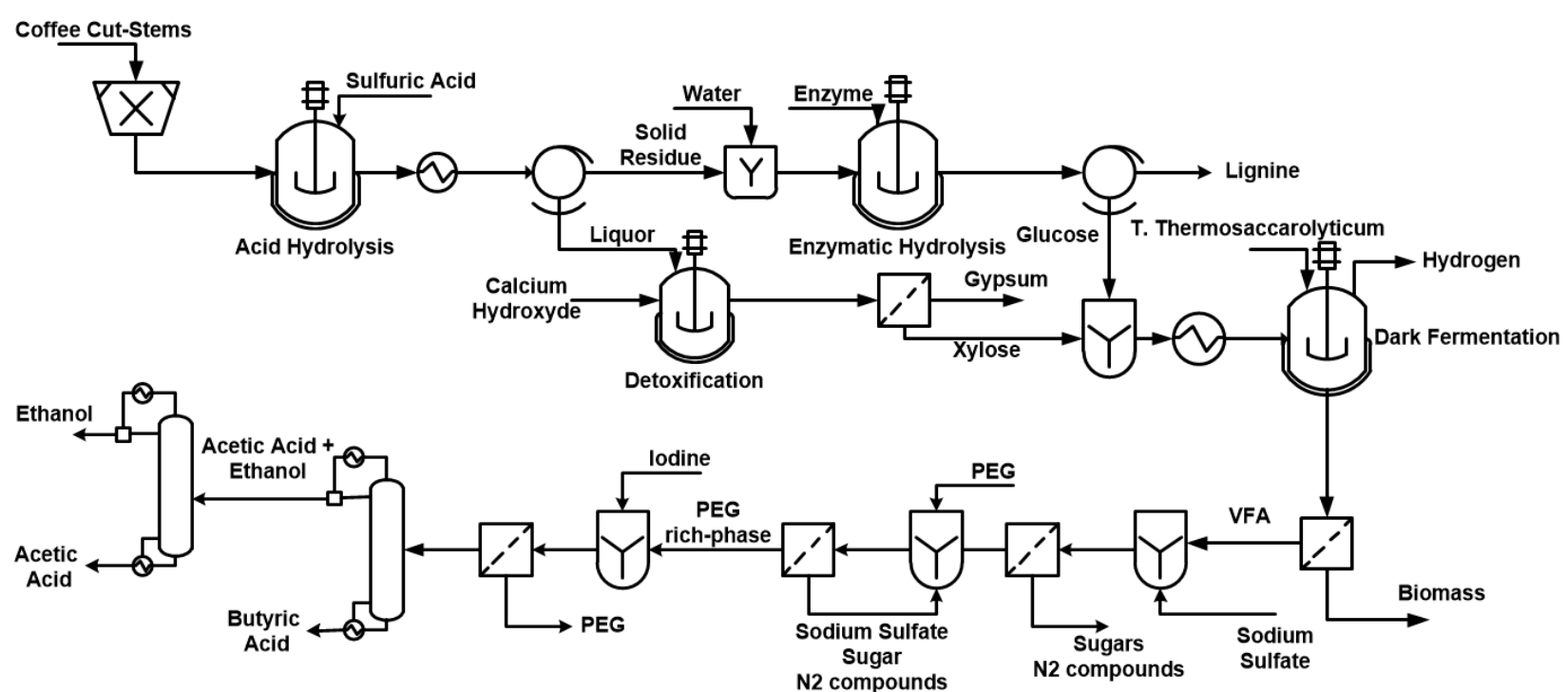

Figure 2. Flowsheet of the hydrogen, acetic acid, butyric acid and ethanol production through dark fermentation of CCS

butyric acid, acetic acid, ethanol and PEG. An iodine solution was added to the organic phase to precipitate the PEG. The filtrate from the solution contained butyric acid, acetic acid and ethanol and subsequently, were submitted to a distillation system to obtain butyric acid (95\%), acetic acid (86\%) and ethanol (98\%). The process scheme for hydrogen, acetic acid, butyric acid and ethanol production is presented in Figure 2.

\section{Techno-Economic Assessment}

A basic equipment mapping adapted to the economic conditions (tax rate, interest of return, operator and supervisor wages, among others) in Colombia was performed to determine the operating costs of the proposed scenarios including the raw material, utilities, labor and maintenance, general plant and administrative costs. Additionally, the depreciation of the equipment was evaluated considering a project life of 10 years. The mass and energy balances from the simulation procedure were used as a starting point for the economic assessment using the software Aspen Process Economic Analyzer v8.0 (Aspen Technology, Inc, USA). The utility costs are linked to the heating and cooling requirements of the process, which were obtained from the energy balance in the software Aspen Energy Analyzer (Aspen Technology, Inc., USA).

The economic assessment of the scenarios was performed considering the contribution of the different economic parameters (e.g. raw material costs, utility costs, labors costs, among others) to the total production cost of the process. Additionally, the revenue of the scenarios was evaluated taking into account the expenses and the sales of main products and by-products of the stand-alone and biorefinery pathways. The production cost of hydrogen and further by-products (ethanol, acetic acid and butyric acid) was determined using economic allocation factors. The main data used in the economic assessment of the proposed scenarios are presented in Table 4. 
Table 4. Utilities, reagents and products market prices

\begin{tabular}{lll}
\hline Component & Price & Units \\
\hline Coffee Cut-Stems & $0.024^{\mathrm{d}}$ & $\mathrm{USD} / \mathrm{Kg}$ \\
\hline Sulfuric Acid & $0.094^{\mathrm{a}}$ & $\mathrm{USD} / \mathrm{Kg}$ \\
\hline Sodium Hydroxide & $0.35^{\mathrm{a}}$ & $\mathrm{USD} / \mathrm{Kg}$ \\
\hline Calcium Hydroxide & $0.05^{\mathrm{a}}$ & $\mathrm{USD} / \mathrm{Kg}$ \\
\hline Sodium Sulfate & $0.077^{\mathrm{a}}$ & $\mathrm{USD} / \mathrm{kg}$ \\
\hline Fuel Ethanol & $0.68^{\mathrm{c}}$ & $\mathrm{USD} / \mathrm{L}$ \\
\hline Acetic Acid $(86 \% \mathrm{w} / \mathrm{w})$ & $0.595^{\mathrm{a}}$ & $\mathrm{USD} / \mathrm{kg}$ \\
\hline Butyric Acid $(95 \% \mathrm{w} / \mathrm{w})$ & $0.2^{\mathrm{a}}$ & $\mathrm{USD} / \mathrm{kg}$ \\
\hline Hydrogen & $4.47^{\mathrm{b}}$ & $\mathrm{USD} / \mathrm{Kg}$ \\
\hline Water & $1.252^{\mathrm{d}}$ & $\mathrm{USD} / \mathrm{m}^{3}$ \\
\hline Electricity & $0.1^{\mathrm{d}}$ & $\mathrm{USD} / \mathrm{kWh}$ \\
\hline Iodine & $30^{\mathrm{a}}$ & $\mathrm{USD} / \mathrm{kg}$ \\
\hline Polyethylene glycol & $2^{\mathrm{a}}$ & $\mathrm{USD} / \mathrm{kg}$ \\
\hline High P. Steam $(105$ bar $)$ & $9.86^{\mathrm{d}}$ & $\mathrm{USD} / \mathrm{ton}$ \\
\hline Mid P. Steam $(30$ bar $)$ & $8.18^{\mathrm{d}}$ & $\mathrm{USD} / \mathrm{ton}$ \\
\hline Low P. Steam $(3 \mathrm{bar})$ & $7.56^{\mathrm{d}}$ & $\mathrm{USD} /$ ton
\end{tabular}

a Prices based on Alibaba International Prices (ALIBABA, 2015)

b Based on hydrogen price projections (McKinsey and Company, 2010)

${ }^{\mathrm{c}}$ Ethanol price based on statistics of the Biofuels National Federation (Federación Nacional de Biocombustibles de Colombia

(Fedecombustibles), 2016)

d Prices adapted to the Colombian context (Aristizábal et al., 2015; Moncada et al., 2013)

\section{Energy Analysis}

From the simulation procedure, the mass balance of the proposed scenarios was determined and subsequently, it was used as starting point of the energy analysis using the software Aspen Plus Energy Analyzer (Aspen Technology Inc., USA) that allows performing the heat exchanger network design to establish the energy targets of the process and also to determine the amount and type of utilities required in the processes in order to supply the energy requirements (heating and cooling).

Additionally, the overall energy efficiency of both scenarios was evaluated considering the energy content of the raw material and the products (hydrogen and ethanol) (scenario 1). It is noteworthy that the acetic and butyric acid are not considered in the energy analysis since these products are used in different chemical applications and thus, they do not have an energy value. Furthermore, the calculation of the energy efficiency was evaluated considering the energy requirements (heating utilities) as an input of the process (scenario 2) as described in Eq. 1.

$$
\eta=\frac{E_{\text {products }}}{E_{\text {biomass }}+E_{\text {utilities }}}
$$

where $E_{\text {products }}$ is the energy content of the products (ethanol and hydrogen), $E_{\text {biomass }}$ is the energy content of the CCS and $E_{\text {utilities }}$ is the energy content of the utilities (i.e. steam). The calculation of each of these parameters was based on the mass flow rate from the simulation procedure and the calorific value (Higher Heating Value) of the compounds (García et al., 2017).

\section{Environmental evaluation}

The potential environmental impact (PEI) is a quantitative indicator of the environmental friendliness or unfriendliness of a process (Young and Cabezas, 1999). This indicator provides an insight of the negative or positive effect of the overall energy balance of both scenarios in the environment. For this purpose, the simulation tool Waste Reduction Algorithm (WAR) (Environmental Protection Agency (EPA), USA) was used in order to evaluate the mass and energy balance of the process and to determine whether or not the process is environmentally friendly. WAR algorithm evaluates the PEI in terms of eight categories: Human toxicity by ingestion (HTPI), human toxicity by dermal exposition or inhalation (HTPE), aquatic toxicity potential (ATP), Global warming (GWP), Ozone depletion potential (ODP), Photochemical oxidation potential (PCOP) and acidification Potential (AP).

\section{RESULTS AND DISCUSSIONS}

Table 5 presents the overall performance of the evaluated scenarios in terms of the productivity and yields of the main products from the dark fermentation. It is evidenced that the production of hydrogen $\left(200.9 \mathrm{cum} \mathrm{H}_{2}\right.$ ton $^{-}$ ${ }^{1} \mathrm{CCS}$ ) is low due to several factors such as the microorganism productivity, batch operation mode, among others. 
Table 5. Productivity and yields of the CCS scenarios

\begin{tabular}{lcccc}
\hline \multirow{2}{*}{ Scenarios } & \multicolumn{2}{c}{ Productivity $^{\mathbf{a}}$} & \multicolumn{2}{c}{ Yields $^{\mathbf{a}}$} \\
\cline { 2 - 5 } & Value & Units & Value & Units $^{\text {Scenario 1 }}$ \\
\hline \multirow{2}{*}{ Scenario 2c } & $136,057 \mathrm{~b}$ & cum $\mathrm{H}_{2} /$ day & 200.9 & $\mathrm{H}_{2} /$ ton CCS \\
\cline { 2 - 5 } & 111.97 & Ton Acetic Acid/day & 0.165 & Ton Acetic Acid/ton CCS \\
\cline { 2 - 5 } & 59.98 & Ton Butyric Acid/day & 0.089 & Ton Butyric Acid/ton CCS \\
\hline
\end{tabular}

a Calculated based on 677.4 Ton CCS/day

b Hydrogen density $0.09 \mathrm{~kg} / \mathrm{cum}$ at normal temperature and pressure (NTP)

c Hydrogen productivity and yield have the same value than scenario 1

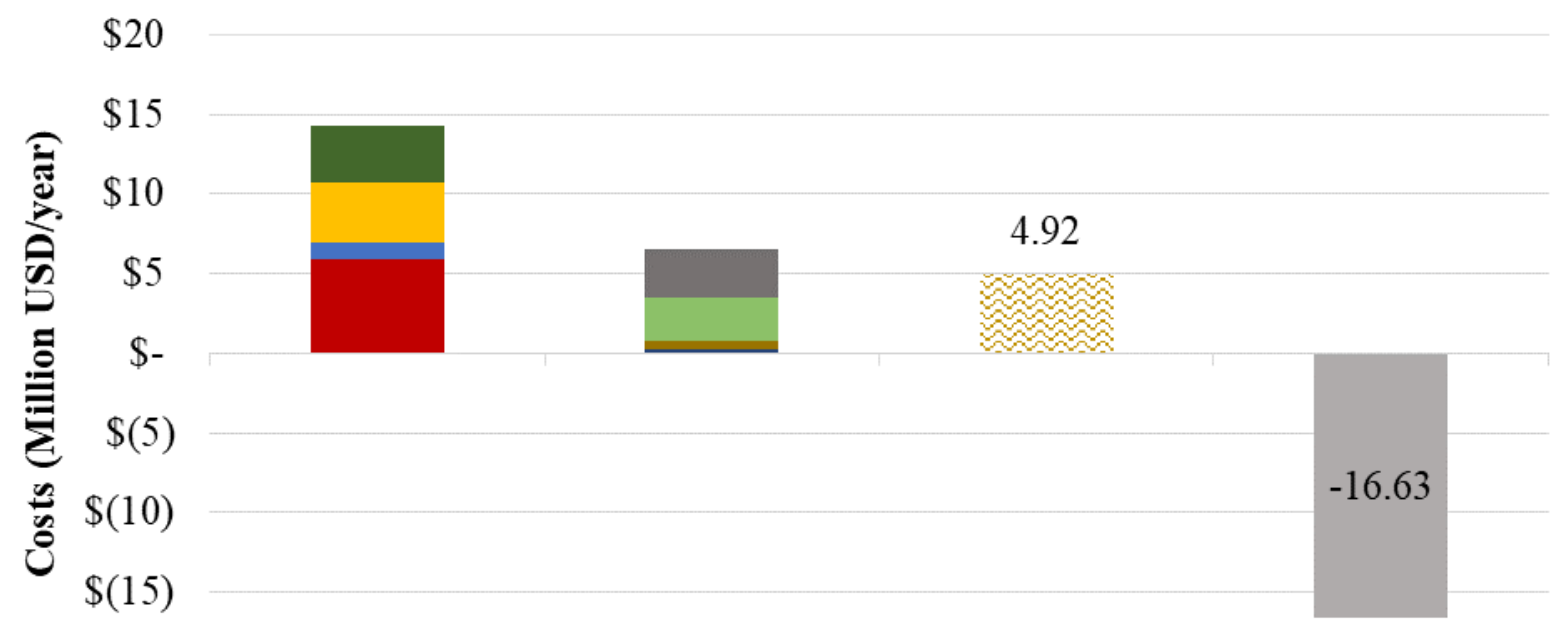

$\$(20)$
Raw Material
Utilities
Hydrogen
Production
Revenues

- CCS

- Electricity

- Slaked Lime

Sulfuric Acid

- Process Water

LP Steam

MP Steam

- Cooling Water

Figure 3. Overview of the stand-alone hydrogen production costs and revenues

However, high hydrogen selectivity was obtained since only hydrogen and carbon dioxide are the main gaseous species in comparison to thermochemical processes, where a gaseous mixture (syngas) is obtained and subsequently, an energy-intensive separation process is required to separate the hydrogen (García et al., 2015). On the other hand, a relatively high content of other metabolites such as ethanol, acetic acid and butyric acid was obtained. Acetic acid was the metabolite with the highest yield ( 0.165 ton Acetic Acid/ton CCS) followed by the butyric acid ( 0.089 ton Butyric Acid/ton CCS) because of the metabolic pathway of the microorganism that tends to produce more Acetyl-CoA and subsequently, acetate and butyrate (O-Thong et al., 2008). In this sense, it is reasonable to think that these by-products, which are obtained at high concentrations, can improve the overall performance of the biorefinery scenario.

\section{Economic Assessment}

Figures 3 and 4 present the general overview of the hydrogen production costs and revenues of the standalone and biorefinery scenarios, respectively. The economic parameters that influence the most the hydrogen production cost in the stand-alone scenario (Figure 3) are the raw material and utility costs. Raw material costs contribute with the $64 \%$ of the total hydrogen production cost. Within these costs, CCS and sulfuric acid market prices have the strongest influence on the production cost. Mid - Pressure Steam and cooling water have the highest contribution to the utility costs, which account for $32 \%$ of the total hydrogen production cost. The remaining parameters (e.g. Maintenance, Labor, Fixed and General, Overhead, and Capital Depreciation Costs) do not have a representative contribution to the hydrogen production cost. From this analysis, it is expected hydrogen sales accounting to 4.92 Million USD per year; however, the revenues of the stand-alone process are negative (16.63 Million USD per year) making this process economically unfeasible due to the low productivity, raw material and utility requirements. From this scenario, a hydrogen production cost of 19,283 USD/ton was calculated, which it is almost 5 times higher than the market price (4,400 USD/ton) (McKinsey and Company, 2010). 


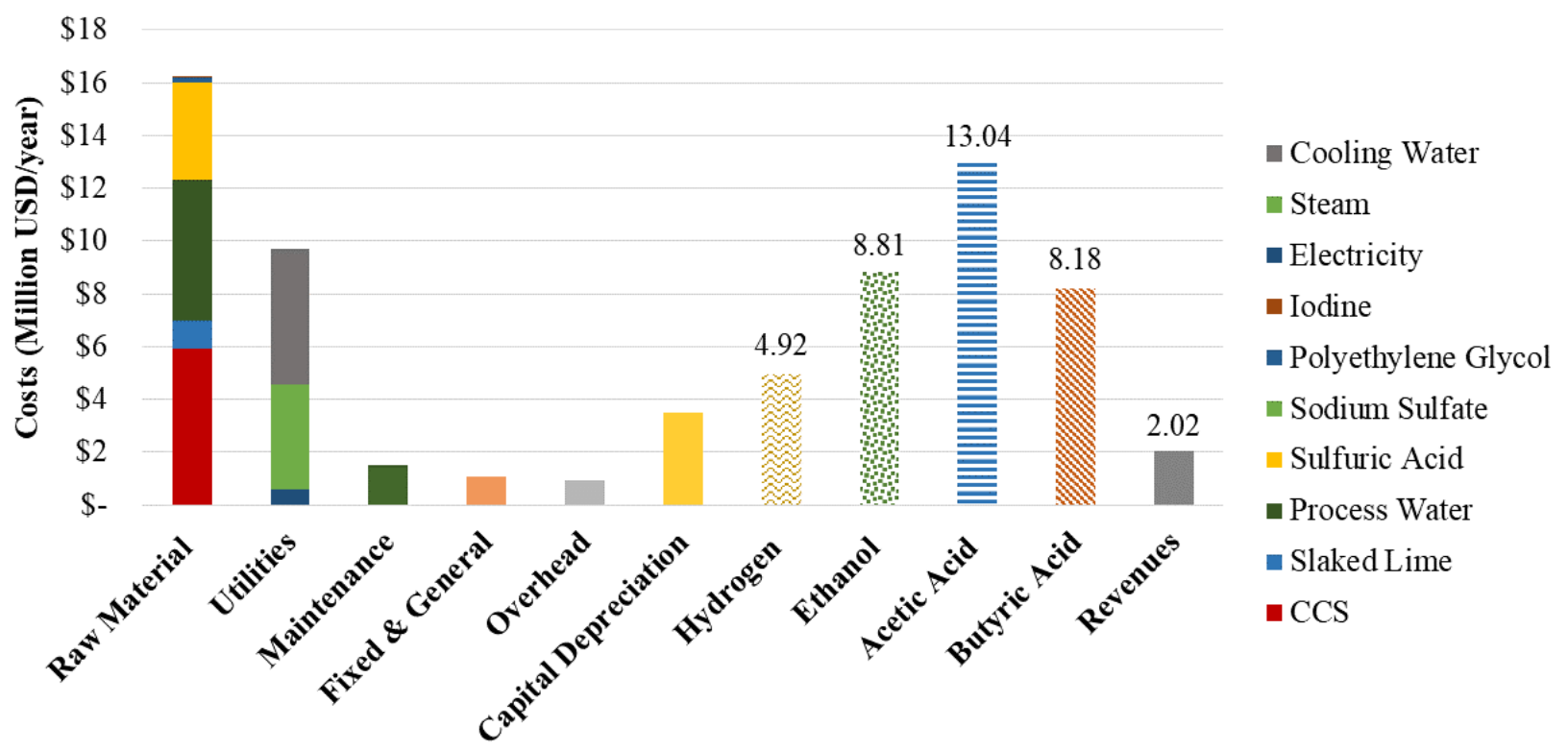

Figure 4. Overview of the hydrogen production costs and revenues under the biorefinery concept

Table 6. Heating and cooling requirements of the evaluated scenarios

\begin{tabular}{lcc}
\hline \multirow{2}{*}{ Energy Requirements } & Scenario 1 & Scenario 2 \\
\cline { 2 - 3 } & Teating & Target Load (kJ/h) \\
\hline Low-Pressure Steam & $8.86 \times 10^{7}$ & $2.58 \times 10^{8}$ \\
\hline Medium-Pressure Steam & $7.51 \times 10^{7}$ & $6.85 \times 10^{7}$ \\
\hline Cooling & & $3.88 \times 10^{8}$ \\
\hline Cooling Water & $2.25 \times 10^{8}$ & \\
\hline
\end{tabular}

In the biorefinery production of hydrogen, the raw material and utility costs also represent the highest contribution to the hydrogen production costs accounting to $49 \%$ and $29 \%$, respectively. Other parameters such as Maintenance, General and Fixed, Overhead and Capital Depreciation costs have a significant contribution to the hydrogen production costs as described in Figure 4. From this scenario, different products (hydrogen, ethanol, acetic acid and butyric acid) are obtained and therefore, it is expected total sales of 34.95 Million USD per year between all the products of the biorefinery. The revenues from the biorefinery scheme are positive (2.02 Million USD per year) and therefore, the profitability of the hydrogen production was improved due to the valorization of secondary metabolites from the fermentation broth. The lowest hydrogen cost was calculated from the biorefinery scenario (4,174 USD per ton) along with the production of ethanol (817 USD per ton), acetic acid (564 USD per ton) and butyric acid (189 USD per ton). The hydrogen cost in this scenario is attractive for stakeholders due to the competitive cost in comparison to the market prices (4,400 USD per ton).

\section{Energy Analysis}

Most of the fermentative processes are high-energy consumption, especially, heating processes (e.g. pretreatment and fermentation stages) and downstream processes (e.g. distillation, evaporation, among others). Table 6 presents the energy requirements of the evaluated scenarios. Scenario 2 has the highest energy targets of the proposed scenarios due to the high heating requirements from the pretreatment (acid and enzymatic hydrolysis), fermentation and separation of VFA's from the fermentation broth. The use of low-pressure steam increases almost three times from the scenario 1 to scenario 2 due to the additional downstream processing of the metabolites from the fermentation broth. The use of cooling water also increases because of the metabolite separation scheme.

Table 7 presents the results from the calculation of the energy efficiency of both scenarios. Scenario 2 has the highest energy efficiency in both cases because of the valorization of the secondary metabolites in the fermentation broth (ethanol). However, the efficiency of the scenario 2 reduces $36 \%$ when the heating requirements are considered in the calculation, whereas the efficiency of scenario 1 reduces $23 \%$. Despite the relatively high energy efficiency of the dark fermentation under the biorefinery concept, the process should be improved aiming to compete with other biochemical routes for bioenergy such as ethanol fermentation (25 - 45\%) (Foust et al., 2009). Besides, a cogeneration scheme coupled to the biorefinery is required in order to improve the energy performance and thus, the economic feasibility since fewer utilities are required. 
Table 7. Energy analysis of the stand-alone and biorefinery pathway for hydrogen production

\begin{tabular}{ccc}
\hline Energy Efficiency & Scenario 1 & Scenario 2 \\
\hline Efficiency 1 & $10.9 \%$ & $17.0 \%$ \\
\hline Efficiency 2 & $8.4 \%$ & $10.8 \%$ \\
\hline
\end{tabular}

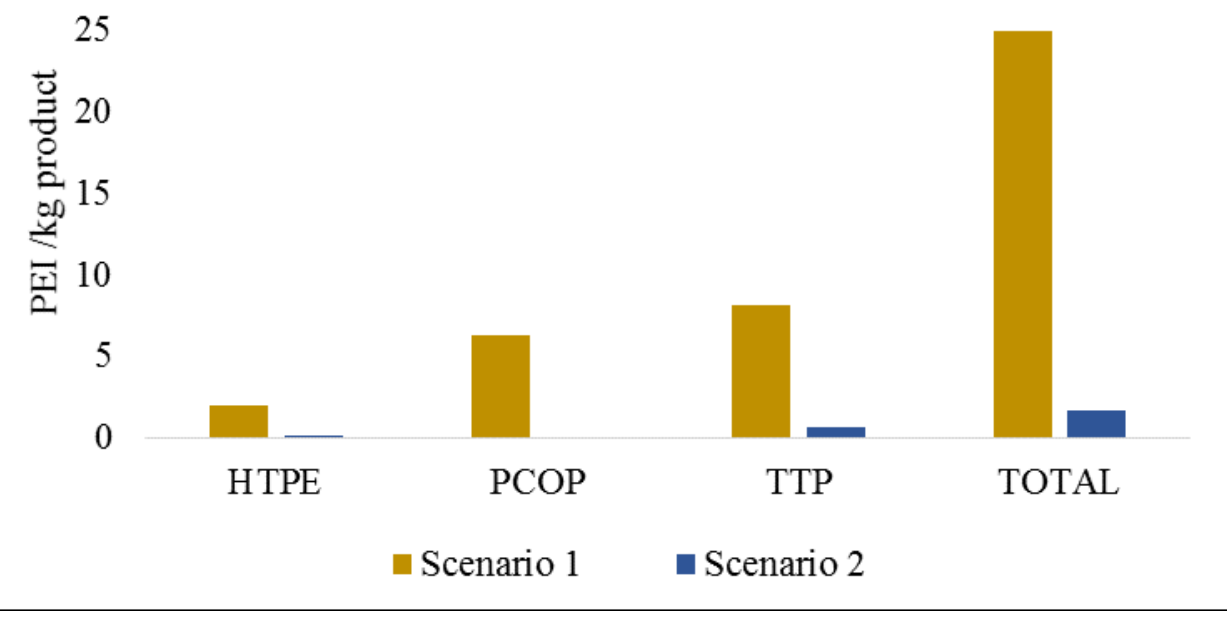

Figure 5. Environmental impact of the evaluated scenarios

\section{Environmental Assessment}

The main residues from the fermentation scenarios are solid wastes (mainly, lignocellulosic components), sulfuric acid, gypsum and volatile fatty acids that have a direct influence in the emissions into water and land sources. In this sense, different environmental impact categories were evaluated for the dark fermentation scenarios such as acidification, photochemical oxidation and human toxicity using the Waste Reduction Algorithm (WAR) that evaluates the potential environmental impact of the processes if the outlet streams were submitted directly into the atmosphere. The evaluated categories (section 2.5) were selected since the fermentation waste streams have high organic burdens that have the most notorious impact in these categories. Figure 5 presents the potential environmental impact of the dark fermentation scenarios based on the three selected impact categories. Due to the valorization of the secondary metabolites from the fermentation broth, the potential environmental impact of the dark fermentation scenarios decreases from the scenario 1 to 2 .

The impact categories that have the highest contribution to the total potential environmental impact are TTP and PCOP. The lethal-dose that produces death in $50 \%$ of rats by oral ingestion $\left(\mathrm{LD}_{50}\right)$ is used as an estimate for the TTP (Young and Cabezas, 1999). The $\mathrm{LD}_{50}$ for ethanol is $7,060 \mathrm{mg} / \mathrm{kg}$, which is the highest dose in comparison to the other by-products from the fermentation broth: acetic acid and butyric acid with $\mathrm{LD}_{50}$ of 3310 and 2000 $\mathrm{mg} / \mathrm{kg}$, respectively. Consequently, the separation of ethanol and the valorization of the other secondary metabolites in the scenario 2 reduce the TTP in comparison to the scenario 1 . The PCOP or smog formation potential is determined by comparing the rate at which a unit mass of chemical reacts with hydroxyl radical $(\mathrm{OH} \cdot)$ to the rate at which a unit mass of ethylene reacts with $\mathrm{OH}$ - (Young and Cabezas, 1999). The main components involved in the smog formation are the volatile organic compounds (VOC's), which are categorized in alkanes, olefins, alkynes, aromatics, alcohols, aldehydes and hydrocarbons. Ethanol and acetic acid are some of the volatile organic compounds that are included in the dark fermentation scenarios; therefore, their contribution to the environmental potential impact is reflected in scenario 1, where their valorization is not considered. Ethanol seems to be the component that has the highest contribution to the PCOP based on the PEI reduction from scenario 1 to 2 that accounts for $99.6 \%$ of the environmental impact of the scenario 1.

\section{CONCLUSIONS}

Biochemical processes require more research not only in terms of productivity but also in the proper valorization of secondary metabolites from the fermentation broth. The best scenario for hydrogen production through dark fermentation considers the separation of ethanol, acetic and butyric acid from the fermentation broth along with the production of hydrogen. Due to the valorization of the secondary metabolites (scenario 2), the hydrogen production cost decreases and the potential environmental impact is also reduced in comparison with the stand-alone production of hydrogen. A hydrogen production cost of 4.17 USD kg-1 was obtained using CCS 
as raw material. The separation of secondary metabolites could not be energetically favorable since high amount of energy is needed to separate these by-products from the fermentation broth. However, the environmental impact of the biorefinery scenario was mitigated when the valorization of the by-products was considered. The impact categories that contribute the most to the total environmental impact were the human toxicity by dermal exposition or inhalation (HTPE), photochemical oxidation potential (PCOP) and terrestrial toxicity potential (TTP).

\section{ACKNOWLEDGEMENTS}

The authors want to acknowledge to the Dirección de Investigación (DIMA) of the Universidad Nacional de Colombia Sede Manizales for the financial support through the project entitled "Development of modular small-scale integrated biorefineries to produce an optimal range of bioproducts from a variety of rural, agricultural and agroindustrial residues/wastes with a minimum consumption of fossil energy (SMIBIO)" Grant No. 202010011331.

\section{REFERENCES}

ALIBABA. (2015). International Prices.

Aristizábal, V., Gómez, Á. and Cardona, C. A. (2015). Biorefineries based on coffee cut-stems and sugarcane bagasse: Furan-based compounds and alkanes as interesting products. Bioresource Technology, 196, 480-9. https://doi.org/10.1016/j.biortech.2015.07.057

Balat, M. (2008). Potential importance of hydrogen as a future solution to environmental and transportation problems. International Journal of Hydrogen Energy, 33(15), 4013-4029. https://doi.org/10.1016/j.ijhydene.2008.05.047

Belafibako, K., Bucsu, D., Pientka, Z., Balint, B., Herbel, Z., Kovacs, K. and Wessling, M. (2006). Integration of biohydrogen fermentation and gas separation processes to recover and enrich hydrogen. International Journal of Hydrogen Energy, 31(11), 1490-1495. https://doi.org/10.1016/j.ijhydene.2006.06.022

Cao, G., Ren, N., Wang, A., Lee, D.-J., Guo, W., Liu, B., ..., Zhao, Q. (2009). Acid hydrolysis of corn stover for biohydrogen production using Thermoanaerobacterium thermosaccharolyticum W16. International Journal of Hydrogen Energy, 34(17), 7182-7188. https://doi.org/10.1016/j.ijhydene.2009.07.009

Federación Nacional de Biocombustibles de Colombia (Fedecombustibles). (2016). Statistics of the fuel ethanol price.

Foust, T. D., Aden, A., Dutta, A. and Phillips, S. (2009). An economic and environmental comparison of a biochemical and a thermochemical lignocellulosic ethanol conversion processes. Cellulose, 16(4), 547-565. https:// doi.org/10.1007/s10570-009-9317-x

García, C. A., Betancourt, R. and Cardona, C. A. (2015). Stand-alone and biorefinery pathways to produce hydrogen through gasification and dark fermentation using Pinus Patula. Journal of Environmental Management. https://doi.org/10.1016/j.jenvman.2016.04.001

García, C. A., Moncada, J., Aristizábal Marulanda, V. and Cardona, C. A. (2017). Techno-economic and energetic assessment of hydrogen production through gasification in the Colombian context: Coffee Cut-Stems. International Journal of Hydrogen Energy, 42(9), 5849-5864. https://doi.org/10.1016/j.ijheatmasstransfer.2017.09.038

García, C. A., Peña, Á., Betancourt, R. and Cardona, C. A. (2017). Energetic and environmental assessment of thermochemical and biochemical ways for producing energy from agricultural solid residues: Coffee Cut-Stems case. Journal of Environmental Management. https://doi.org/10.1016/j.jenvman.2017.04.029

Hu, B.-B., Li, M.-Y., Wang, Y.-T. and Zhu, M.-J. (2018). High-yield biohydrogen production from non-detoxified sugarcane bagasse: Fermentation strategy and mechanism. Chemical Engineering Joumal, 335, 979-987. https://doi.org/https://doi.org/10.1016/j.cej.2017.10.157

Kadam, K. L., Rydholm, E. C. and McMillan, J. D. (2004). Development and validation of a kinetic model for enzymatic saccharification of lignocellulosic biomass. Biotechnology Progress, 20, 698-705. https://doi.org/10.1021/bp034316x

Khodaverdi, M., Karimi, K., Jeihanipour, A. and Taherzadeh, M. J. (2012). Kinetic modeling of rapid enzymatic hydrolysis of crystalline cellulose after pretreatment by NMMO. Journal of Industrial Microbiology and Biotechnology, 39(3), 429-438. https:/ / doi.org/10.1007/s10295-011-1048-y

Kumar, G., Shobana, S., Nagarajan, D., Lee, D.-J., Lee, K.-S., Lin, C.-Y., ... Chang, J.-S. (2018). Biomass based hydrogen production by dark fermentation-recent trends and opportunities for greener processes. Current Opinion in Biotechnology, 50, 136-145. https://doi.org/https://doi.org/10.1016/j.copbio.2017.12.024

Lefranc, J. (1928). Process for the extraction of butyric acid and its homologues. France. 
López, J. A., Trejos, V. M. and Cardona, C. A. (2009). Parameters estimation and VLE calculation in asymmetric binary mixtures containing carbon dioxide + n-alkanols. Fluid Phase Equilibria, 275(1), 1-7. https://doi.org/10.1016/j.fluid.2008.09.013

McKinsey and Company. (2010). A portfolio of power-trains for Europe: a fact-based analysis - The role of Battery Electric Vehicles, Plug-in Hybrids and Fuel Cell Electric Vebicles. Fuel Cell. Available at: http:/ /www.zeroemissionvehicles.eu/

Moncada, J., El-Halwagi, M. M. and Cardona, C. A. (2013). Techno-economic analysis for a sugarcane biorefinery: Colombian case. Bioresource Technology, 135, 533-543. https://doi.org/10.1016/j.biortech.2012.08.137

Nissilä, M. E., Lay, C. H. and Puhakka, J. a. (2014). Dark fermentative hydrogen production from lignocellulosic hydrolyzates - A review. Biomass and Bioenergy, 67, 145-159. https://doi.org/10.1016/j.biombioe.2014.04.035

O-Thong, S., Prasertsan, P., Karakashev, D. and Angelidaki, I. (2008). Thermophilic fermentative hydrogen production by the newly isolated Thermoanaerobacterium thermosaccharolyticum PSU-2. International Journal of Hydrogen Energy, 33, 1204-1214. https://doi.org/10.1016/j.ijhydene.2007.12.015

Parthasarathy, P. and Narayanan, K. S. (2014). Hydrogen production from steam gasification of biomass: Influence of process parameters on hydrogen yield - A review. Renewable Energy, 66, 570-579. https://doi.org/10.1016/j.renene.2013.12.025

Purwadi, R., Niklasson, C. and Taherzadeh, M. J. (2004). Kinetic study of detoxification of dilute-acid hydrolyzates by $\mathrm{Ca}(\mathrm{OH})$ 2. Journal of Biotechnology, 114, 187-198. https:// doi.org/10.1016/j.jbiotec.2004.07.006

Rafiqul, I. S. M. and Mimi Sakinah, A. M. (2012). Kinetic studies on acid hydrolysis of Meranti wood sawdust for xylose production. Chemical Engineering Science, 71, 431-437. https://doi.org/10.1016/j.ces.2011.11.007

Ren, N. Q., Cao, G. L., Guo, W. Q., Wang, A. J., Zhu, Y. H., Liu, B. F. and Xu, J. F. (2010). Biological hydrogen production from corn stover by moderately thermophile Thermoanaerobacterium thermosaccharolyticum W16. International Journal of Hydrogen Energy, 35(7), 2708-2712. https:// doi.org/10.1016/j.ijhydene.2009.04.044

Rodríguez, V. N. and Zambrano, F. D. (2010). Los subproductos del café: fuente de energía renovable. Avances Técnicos Cenicafé, 3, 8. https:/ / doi.org/ISSN-0120-0178

Ruggeri, B., Tommasi, T. and Sassi, G. (2010). Energy balance of dark anaerobic fermentation as a tool for sustainability analysis. International Journal of Hydrogen Energy, 35(19), 10202-10211. https://doi.org/10.1016/j.ijhydene.2010.08.014

Sitthikitpanya, S., Reungsang, A., Prasertsan, P. and Khanal, S. K. (2017). Two-stage thermophilic bio-hydrogen and methane production from oil palm trunk hydrolysate using Thermoanaerobacterium thermosaccharolyticum KKU19. International Journal of Hydrogen Energy, 42(47), 28222-28232. https://doi.org/10.1016/j.ijhydene.2017.09.136

Taherzadeh, M. J., Gustafsson, L., Niklasson, C. and Lidén, G. (2000). Inhibition effects of furfural on aerobic batch cultivation of Saccharomyces cerevisiae growing on ethanol and/or acetic acid. Journal of Bioscience and Bioengineering, 90(4), 374-380. https:/ / doi.org/10.1016/S1389-1723(01)80004-9

Triana, C. F., Quintero, J. A., Agudelo, R. A., Cardona, C. A. and Higuita, J. C. (2011). Analysis of coffee cut-stems $(\mathrm{CCS})$ as raw material for fuel ethanol production. Energy, 36(7), 4182-4190. https://doi.org/10.1016/j.energy.2011.04.025

U.S Energy Information Administration (EIA). (2018). Energy Explained - Hydrogen Production.

Urbaniec, K. and Bakker, R. R. (2015). Biomass residues as raw material for dark hydrogen fermentation - A review. International Journal of Hydrogen Energy, 40(9), 3648-3658. https://doi.org/10.1016/j.ijhydene.2015.01.073

Wang, J. and Wan, W. (2009). Kinetic models for fermentative hydrogen production: A review. International Journal of Hydrogen Energy, 34(8), 3313-3323. https:// doi.org/10.1016/j.ijhydene.2009.02.031

Wooley, R. J. and Putsche, V. (1996). Development of an ASPEN PLUS Physical Property Database for Biofuels Components. Victoria, (April), 1-38. https://doi.org/10.2172/257362

Wu, D., Chen, H., Jiang, L., Cai, J., Xu, Z. and Cen, P. (2010). Efficient separation of butyric acid by an aqueous two-phase system with calcium chloride. Chinese Journal of Chemical Engineering, 18(4), 533-537. https://doi.org/10.1016/S1004-9541(10)60255-8

Wu, K.-J. and Chang, J.-S. (2007). Batch and continuous fermentative production of hydrogen with anaerobic sludge entrapped in a composite polymeric matrix. Process Biochemistry, 42(2), 279-284. https://doi.org/10.1016/j.procbio.2006.07.021

Wu, X., Li, G., Yang, H. and Zhou, H. (2015). Study on extraction and separation of butyric acid from clostridium tyrobutyricum fermentation broth in PEG/Na2SO4 aqueous two-phase system. Fluid Phase Equilibria, 403, 3642. https://doi.org/10.1016/j.fluid.2015.05.047

Young, D. M. and Cabezas, H. (1999). Designing sustainable processes with simulation: the waste reduction (WAR) algorithm. Computers \& Chemical Engineering, 23, 1477-1491. https://doi.org/10.1016/S00981354(99)00306-3 
Zhang, Z., Li, Y., Zhang, H., He, C. and Zhang, Q. (2017). Potential use and the energy conversion efficiency analysis of fermentation effluents from photo and dark fermentative bio-hydrogen production. Bioresource Technology, 245, 884-889. https:// doi.org/10.1016/j.biortech.2017.09.037

Zheng, Y., Pan, Z., Zhang, R. and Jenkins, B. M. (2009). Kinetic modeling for enzymatic hydrolysis of pretreated creeping wild ryegrass. Biotechnology and Bioengineering, 102(6), 1558-1569. https://doi.org/10.1002/bit.22197 